\section{Effect of limited peripheral cues on stereoacuity*}

\author{
S. M. LURIA \\ Naval Submarine Medical Center, Groton, Conn. 06340
}

Stereoacuity is markedly reduced when Os are required to view the test apparatus in a Ganzfeld. The addition of a limited number of peripheral stimuli into the Ganzfeld significantly improves acuity.

Several investigators have hypothesized that foveal stereoacuity is degraded by a lack of peripheral stimulation (Goldstein, Clahane, \& Sanfilippo, 1966; Luria \& Kinney, 1968). To test this, Luria (1969) measured stereoacuity as various amounts of the peripheral field were screened from S's view; as more and more of the periphery was screened by reducing the aperture in a sheet of cardboard close to O's eyes, stereoacuity progressively declined.

Recently, Hennessy \& Leibowitz (1971) investigated magnitude of accommodation while Os viewed a fixation spot through apertures located at various distances. They found that accommodation was a compromise between the distance of the fixation spot and that of the aperture through which it was viewed.

These findings raise the question of whether Luria's (1969) results were due simply to the presence of an aperture close to $O$ 's eyes rather than to the elimination of peripheral stimuli. That is, had the peripheral cues been eliminted without such an aperture, would there have been no decline in acuity?

The present experiment has sought to answer these questions by introducing peripheral stimuli into the "Ganzfeld" situation produced by the type of aperture arrangement used previously to see if acuity is thereby improved despite the continued presence of the aperture.

APPARATUS AND PROCEDURE

Stereoacuity was measured with a three-rod Howard-Dolman apparatus under three viewing conditions: (1) unrestricted-O was permitted full view of the laboratory; (2) "Ganzfeld"-an attempt was made to produce a featureless field of view around the test apparatus by having $O$ look through a small circular aperture in a white hemisphere which afforded him a view only of a white screen with

* From Bureau of Medicine and Surgery, Navy Department, Research Work Unit M4306.03-2050D. The opinions or assertions contained herein are the private ones of the author and are not to be construed as official or reflecting the views of the Navy Department or the Naval Service at large.

a rectangular window through which the rods of the Howard-Dolman were visible (see Fig. 1); (3) stimuli on screen-viewing conditions were identical to the "Ganzfeld" condition, except that large photographs taken from a magazine were hung on the screen as far in the periphery as possible on either side of the window.

The field of view through the circular aperture subtended about $20 \mathrm{deg}$ of visual angle. The rectangular opening was $2.4 \times 6.6 \mathrm{deg}$, revealing the three black rods against a flat white background illuminated to about $1 \mathrm{fL}$. Lamps to either side of the screen were adjusted so as to match its brightness to that of the Howard-Dolman background, and the Howard-Dolman apparatus (HD).

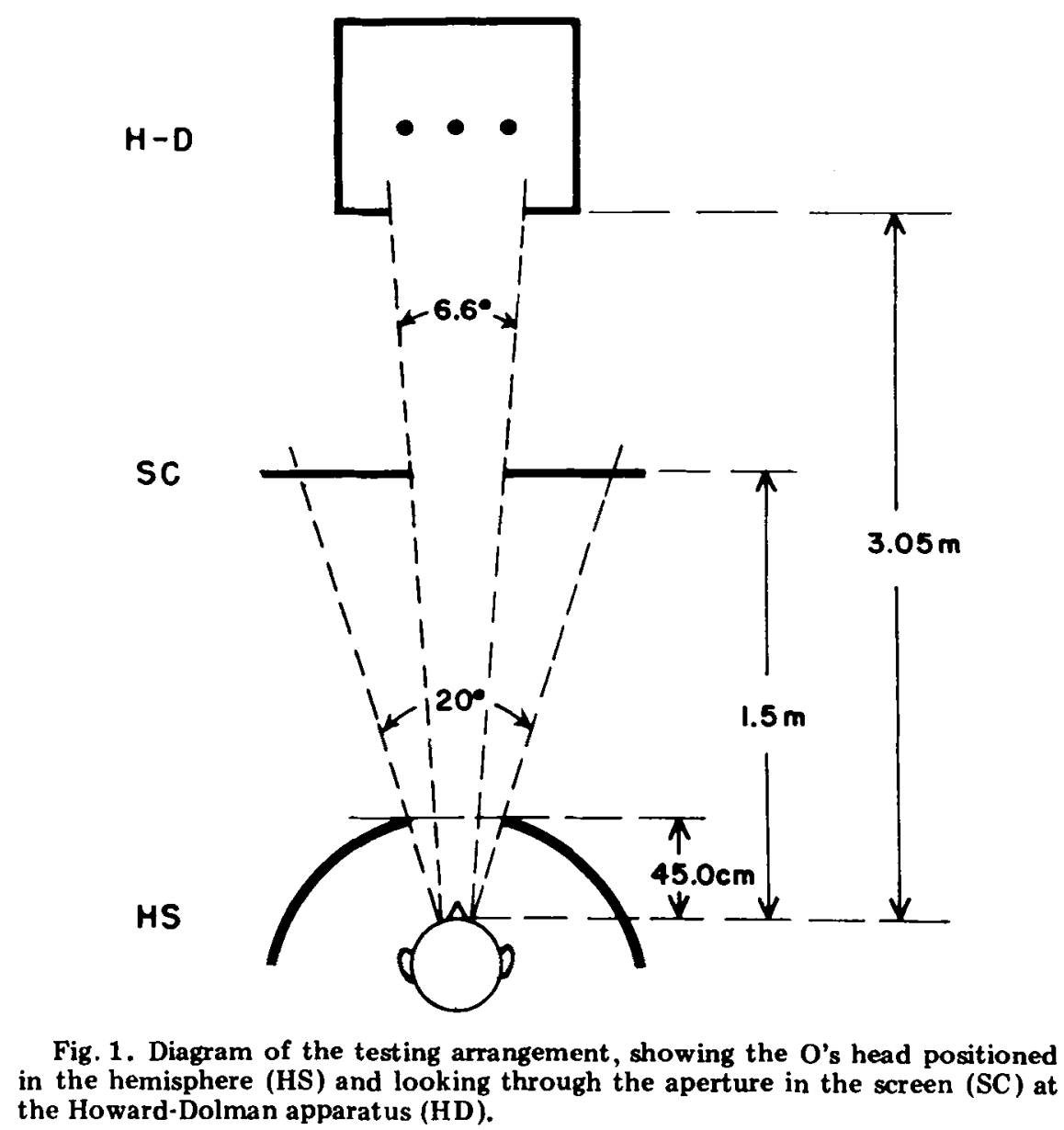

Fig. 1. Diagram of the testing arrangement, showing the $O$ 's head positioned in the hemisphere (HS) and looking through the aperture in the screen (SC) at

another light above $\mathrm{O}$ was adjusted to match the interior of the hemisphere to the screen. With all lights so adjusted, it was possible to discern the outlines of the apertures, but they were extremely unobtrusive, particularly when attention was centered on the rods.

The distance of the screen was set at $1.5 \mathrm{~m}$ simply because that was the greatest distance at which the largest sheet of cardboard available could be set without its edges becoming visible. At a greater distance, two sheets would have been necessary, and it was feared that the seam would provide an unwanted cue.

The three conditions were given in a different random order during one session to each $O$. A short rest period intervened between conditions while the screens and lights were adjusted.

Thresholds were measured by the method of constant stimuli. The middle rod was set at various positions, and at each setting $O$ was required to judge whether it was closer or farther than the outside rods. A frequency-of-seeing curve was drawn on cumulative probability paper, and the $50 \%$ value was taken as the equidistance setting. The standard deviations of the thresholds could then 
Table 1

Precision of Stereoacuity $\left(\eta_{0}\right.$ in Seconds of Arc)

\begin{tabular}{lccc}
\hline & $\begin{array}{c}\text { Unrestricted } \\
\text { Field of } \\
\text { View }\end{array}$ & "Ganzfeld" & $\begin{array}{c}\text { Stimuli } \\
\text { on } \\
\text { Screen }\end{array}$ \\
\hline AM & 14.3 & 50.1 & 35.8 \\
CC & 3.6 & 7.2 & 5.4 \\
TM & 10.7 & 21.5 & 9.7 \\
AR & 5.7 & 5.7 & 5.7 \\
BR & 7.2 & 9.0 & 2.9 \\
DJ & 7.2 & 9.0 & 12.5 \\
DK & 4.7 & 17.9 & 14.3 \\
EL & 3.6 & 12.5 & 3.6 \\
EA & 2.8 & 14.3 & 15.4 \\
AG & 1.8 & 5.4 & 2.5 \\
Mean & 6.2 & 15.3 & 10.8 \\
\hline
\end{tabular}

be read directly from the graph. The results are given in terms of the variability, which appears to be a more sensitive measure than localization error.

\section{OBSERVERS}

Five staff members (the first five in Table 1) and five sailors served as Os. Only three (A.R., C.C., and B.R.) had taken part in previous stereoacuity experiments in this series.

RESULTS AND DISCUSSION

Table 1 gives the standard deviations of the settings for the three conditions. Restricting the field of view degraded the precision of the equidistance setting for every $O$ except A.R., whose thresholds remained unchanged during the experiment. When the two photographs were added to the restricted field, precision improved for all but two of the other nine Os. These changes were highly significant, according to a Friedman two-way analysis of variance by ranks $\left(\chi_{r}^{2}=10.55, \mathrm{df}=2, \mathrm{p}<.01\right)$, but, of course, much of the variance is attributable to the great improvement in precision when the field of view is unrestricted, as reported previously (Luria, 1969).

of primary importance for this study is the comparison between only the two restricted viewing conditions. The addition of the peripheral stimuli to the "Ganzfeld" condition resulted in a significant improvement in acuity ( $p<.025$, Wilcoxon, one-tailed), despite the fact that the aperture was still present.

It should be pointed out that these results do not, of course, indicate to what extent the drop in acuity in the "Ganzfeld" condition is the result of the lack of peripheral stimuli and how much is due to the presence (however faint) of the apertures. It is possible that acuity is improved by the additional stimuli only because they are closer to the target than the aperture and of higher contrast-thus exerting a stronger effect on accommodation. But by the same token, it may be noted that in Hennessy and Leibowitz's study, the fixation spot was $6 \mathrm{fL}$, whereas the screen was $16 \mathrm{fL}$; the brighter screen may have exerted more of an influence on accommodation in their results than was the case in the experiments in this laboratory, where the various surfaces were matched for brightness.

In any event, although the apertures make uncertain what the minimal conditions are for completely corrected stereoacuity, it is clear that the introduction of a limited number of peripheral stimuli into a highly restricted visual field does significantly improve it.

\section{REFERENCES}

GOLDSTEIN, J. H., CLAHANE, A. C., \& SANFILIPPO, $S$. The role of the periphery in binocular vision. American Journal of Ophthalmology, 1966, 62. 702-706.

HENNESSY, R. T., \& LEIBOWITZ, H. W. The effect of a peripheral stimulus on accommodation. Perception \& Psychophysics, 1971, 10, 129-132.

LURIA, S. M. Stereoscopic and resolution acuity with various fields of view. Science, 1969, 164, 452-453.

LURIA, S. M., \& KINNEY, J. A. S. Stereoscopic acuity underwater. American Journal of Psychology. 1968. 81, 359-366. 